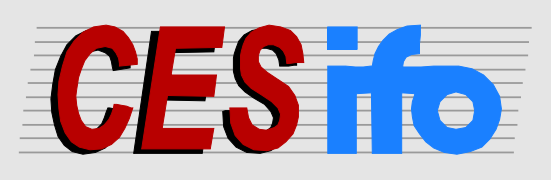

\title{
Working
}

Papers

www.cesifo.org/wp

\section{He's a Chip Off the Old Block - The Persistence of Occupational Choices Across Generations}

\author{
Bodo Knoll \\ Nadine Riedel \\ Eva Schlenker
}

CESIFO WORKING PAPER NO. 4428

CATEGORY 5: ECONOMICS OF EDUCATION

OCTOBER 2013

An electronic version of the paper may be downloaded

- from the SSRN website:

- from the RePEc website:

- from the CESifo website:

WwW.SSRN.com

www.RePEc.org

www.CESifo-group.org/wp

\section{CESifo}




\title{
He’s a Chip Off the Old Block - The Persistence of Occupational Choices Across Generations
}

\begin{abstract}
The purpose of this paper is to assess intergenerational occupational mobility in Germany. Using data from the Socioeconomic Panel (SOEP), we find a high persistence of occupational choices across fathers and children. To separate effects related to parental advice and influence (nurture) from genetic factors (nature), we determine the persistence separately for children who grew up with their biological fathers and those who did not. The results suggest that nurture-related effects explain a significant fraction of the observed correlation of fathers' and children's occupational choices. We discuss policy implications that follow from the analysis.
\end{abstract}

JEL-Code: J240, J620.

Keywords: occupational choice, German SOEP, parental educational investment.

\author{
Bodo Knoll* \\ University of Hohenheim \\ Stuttgart / Germany \\ bodo.knoll@uni-hohenheim.de
}

\author{
Nadine Riedel \\ University of Hohenheim \\ Stuttgart / Germany \\ nadine.riedel@uni-hohenheim.de
}

\author{
Eva Schlenker \\ University of Hohenheim \\ Stuttgart / Germany \\ eva.schlenker@uni-hohenheim.de
}

*corresponding author

$7^{\text {th }}$ October 2013 


\section{Introduction}

Recent decades have seen the emergence of a flourishing empirical literature which assesses the intergenerational transmission of educational attainment (see Scarr and Weinberg (1994), Sacerdote (2002), Das and Sjogren (2002), Plug (2004), Plug and Vijverberg (2005), Sacerdote (2007) and Björklund et al. (2006)). From a policy perspective, it is decisive to understand whether the observed intergenerational correlation reflects persistency of genetic endowments or environmental factors, as only the latter offer a possible role for public policy to influence educational outcomes, and hence the economic and social status of individuals. Recent papers empirically distinguish between nature- and nurture-related effects in this context, commonly finding that both components influence the variation in school attainment (see e.g. Black and Devereux (2011) for a survey and the papers cited above).

Conditional on educational attainment, individuals still have to choose among a wide array of occupations though. Individuals with a university entry certificate for example have to decide whether to become a doctor, lawyer, teacher etc. From a welfare perspective, occupational decisions are of utmost importance since the quality of the match between individuals and occupations may affect their productivity and wages as well as other socio-economic characteristics later in life. This is especially relevant for the rigid labor markets of many European countries where career opportunities strongly depend on formal occupational training and switching occupations later in life involves considerable costs.

The identification of the determinants of occupational choices has received comparably little attention in the labor economics literature so far. The present paper contributes to a small literature strand that investigates intergenerational occupational transmission and thus the role of the family in determining individual occupational decisions. Occupational choices are made early in life, when the individual usually still lives with his/her parents, who financially support the vocational education and training. They may thus influence the occupational decision, potentially biasing the offspring's choice towards their own occupations. ${ }^{1}$ To ensure the stability of familyowned businesses, parents may, for example, want their children to choose vocational training that enables them to take over the family business later in life. Working in the same occupation may also increase the bonding within the family as parents and children share professional interests and experiences. Children may moreover be biased towards their parents' occupations in anticipation of benefiting from their parents'

\footnotetext{
${ }^{1}$ Recent studies suggest that individuals account for reputation effects in their personal environment when deciding on vocational training (see Corneo and Jeanne (2009), Doepke and Zilibotti (2008)).
} 
professional network. ${ }^{2}$ And parents are in general a natural and important source of advice and information. Given that the search for credible information is costly and difficult, information shared by parents may bias their children's opinions and decisions. All of the described mechanisms increase the individual's propensity to choose the same occupation as his parents, while they do not necessarily improve the quality of the occupational match. ${ }^{3}$

The aim of this paper is to empirically assess the transmission of occupational choices across generations for Germany using information from the German Socioeconomic Panel (SOEP). The data set comprises rich socio-economic information on children and their parents, including detailed information on the occupational choices of both. Estimating conditional and nested logit models, we find strong evidence in favor of intergenerational occupational transmission. The estimates suggest that the relative probability of choosing an occupation about doubles if the individual's father works in the respective occupation. In order to identify whether the observed intergenerational correlation is determined by the environmental factors and nurture effects described above, the empirical challenge is to disentangle them from factors related to nature and the inheritability of genetic endowments. ${ }^{4}$ Our identification strategy accounts for nature effects by determining the persistence of occupational choices separately for individuals who grew up with their biological parents and individuals who did not. Following previous research, we focus on the intergenerational transmission of the father's occupation, presuming that nature and nurture effects are relevant if the biological father lived in the same household during the individual's childhood, whereas only nature effects are relevant if the father was absent. The nurture-component is then calculated as the difference between the two transmission rates.

In line with the theoretical presumptions, we find that the quantitative effect differs

\footnotetext{
${ }^{2}$ Empirical evidence suggests that parents exploit family and business contacts to advance their children's career, conditional on the occupational choice (see for example Corak and Piraino (2011), Bentolila et al. (2008)).

${ }^{3}$ Especially in the context of the agricultural sector, children may also acquire productivity increasing skills and knowledge in their parent's occupation during childhood which may bias their occupational choice (see e.g. Laband and Lentz (1983), Corak and Piraino (2011), Lentz and Laband $(1989,1990)$ and Laband and Lentz (1992)).

${ }^{4}$ Genes may influence talent or preferences for occupations. While many occupations in agriculture and craft value physical fitness and skills, cognitive abilities and social competencies are important for many occupations in the service sector (see, e.g., Bouchard (2004)). Individuals moreover select into occupations which fit their inherited endowments and talents. People with high self-esteem and high self-efficacy, for example, seek challenging occupations (see Judge and Bono (2001)), while gregarious people tend to choose jobs with many social interactions (see Krueger and Schkade (2008)). Male traits push workers into male-dominated disciplines. Risk aversion accounts for the search for a safe job (see, e.g., DeLeire and Levy (2004), Grazier and Sloane (2008), Antecol and Cobb-Clark (2010) Boehm and Riedel (2012)).
} 
significantly across the two groups. Relative to the group of individuals who grew up with their biological father, the father-to-child transmission of occupational choices is reduced by around $25 \%$ for individuals whose father was absent during their youth. We consider the estimate to be a lower bound of the true effect as our baseline specifications include individuals whose biological father is classified as absent, although he might still have been in contact with the child, e.g. after the parents' divorce or separation. In these cases, some nurture component may prevail, thus leading to an underestimation of the overall nurture effect in the context of our model framework. To assess the quantitative importance of this downward bias, we ran robustness checks which restrict the group of individuals with absent fathers to orphans whose father died early during their childhood and for whom nurture effects thus play no role. This leaves the pattern of our results unaffected. Furthermore note that all our estimations condition on the individual's level of school attainment and thus capture nature and nurture components of 'horizontal' occupational choices which go beyond 'vertical' educational decisions. The findings underpin the importance of environmental factors in driving intergenerational occupational transmissions. As discussed above, this may give rise to potentially inferior matches between individuals' skills and occupations; and it offers potential for welfare improving government interventions.

Our paper is closely related to a small literature on intergenerational occupational transmission. Existing papers exploit longitudinal historical data to determine the correlation of occupational choices between fathers and sons and compare the respective persistence across countries and across time (see e.g. Ferrie (2005), Long and Ferrie (2013), and Dunn and Holtz-Eakin (2000)). ${ }^{5}$ However, contrary to our study, existing work accounts for rough occupational groups only (e.g. distinguishing between farmers, white and blue collar workers, see Ferrie (2005)) and does not allow for an explicit separation of nature and nurture components in driving the observed intergenerational correlation. Our paper is also loosely related to a growing literature on corporate performance and the succession in family firms (see e.g. Villalonga and Amit (2006), Bennedsen et al. (2007), Lins et al. (2012), and Andersen et al. (2009)) and to papers that investigate the impact of labor market conditions and individual characteristics, e.g. gender and personality traits, on occupational choice (see, e.g., Robertson and Symons (1990), Drost (2002), Sookram and Strobl (2009), Kleinjans (2010), Polachek (1981) and Anker (1997)).

The remainder of the paper is structured as follows: In Section 2, we present our data set. Section 3 describes the estimation methodology. The estimation results are

\footnotetext{
${ }^{5}$ Intergenerational occupational mobility has also been the the focus of a, mostly descriptive, literature in sociology.
} 
presented in Section 4. Section 5 concludes.

\section{Data Set and Sample Descriptives}

Our analysis relies on the German SOEP which is a nationally representative random sample survey covering more than 11,000 German households. ${ }^{6}$ The SOEP contains detailed information on the family background at the individual level, as every respondent is asked to complete a biography questionnaire. Our analysis is based on a pooled data set from the SOEP waves 1984 to 2010. The sample comprises individuals from Western Germany who were born in 1965 or earlier, and for whom we observe information on their educational and occupational decisions.

The variable of main interest is the occupation chosen by an individual and his/her parents. Following previous research (see e.g. Long and Ferrie (2013)), our empirical analysis exploits information on the occupation of the biological father, as labor market participation of women in Germany during the early and mid 20th century was extremely low. ${ }^{7}$ Information on the biological father's occupation is taken from the individual's biography questionnaire, while information on the individual's own occupation is constructed from his/her job biography. ${ }^{8}$ The SOEP adopts the occupational classification of the German Federal Statistical Office ("Statistisches Bundesamt") introduced in 1992 (Statistisches Bundesamt (1992)). The classification aggregates 4digit industries into 33 occupational groups according to the tasks performed by the worker and the materials used (see Statistisches Bundesamt (1992), p. 13). In the following, we will make use of this classification with the modification that we merge adjacent classes that include very few observations to ensure convergence of our estimation models. Precisely, we merged (1) miners, stone workers, and workers in ceramic and glass industries, (2) workers in chemical, wood, and, paper manufacturing industries, (3) workers in metal production and metal processing, (4) workers in electrical occupations and assemblers, (5) workers in textile, fur, and leather industries, (6) building finishers, workers in wood and plastic processing, and painters, (7) good inspectors, machinists, and workers in elementary occupations, (8) workers in sale of goods and in sale of service, and (9) workers in health services, social work, and education. This leaves us with a total of 19 occupational classes. See Table 1 in the Appendix for a detailed description.

\footnotetext{
${ }^{6}$ See Wagner et al. (2007) for further details.

${ }^{7}$ Information on the mother's occupation is missing for $75 \%$ of the observations.

${ }^{8}$ If individuals worked in several occupations, we use information on the first occupation.
} 
Furthermore, we augment our data by information on age, sex, education and place of residence of the individuals. $52 \%$ of the individuals in our sample are female. On average, individuals attend school for 12 years, including vocational training. Information on the individual's year of birth is added to account for structural changes in occupational choice. The average year of birth is 1947. We also acknowledge regional differences by including a dummy variable indicating individuals in the Northern German states of Schleswig-Holstein, Hamburg, Bremen or Lower Saxony. See Table 2 in the Appendix.

- Tables 2 and 3 about here -

To determine whether intergenerational occupational persistence is driven by nature and nurture effects, we define two subsamples: individuals who were raised in a family where the biological father was living in the same household and individuals who were raised in families where the biological father was absent. Intergenerational occupational persistence in the former sample may reflect nature and nurture components, while intergenerational occupational persistence observed in the latter subsample plausibly reflects nature effects only. Our data includes information on the presence and absence of the biological father. The information is taken from the SOEP's biography questionnaire. Individuals are asked how many years the individual had spent with a single mother, with a stepfather, with other relatives, with foster parents, or in a children's home at the age of 15 . We classify the father as absent if the child has spent at least half of his childhood (eight years or more) without the biological father. ${ }^{9}$ As in most cases fathers do not return after they left the family, the definition implies that the father had been absent during the individual's youth at least for the period from age 7 to 15, thus including the years directly before the individual chose occupational training. In robustness checks, we will assess the sensitivity of our results to alternative definitions of an absent father (see Section 4 for details).

Information on the occupations of individuals and their fathers is available in 6,350 cases. Tables 2 and 3 provide descriptive statistics for the entire sample and for the two subsamples of individuals who did and did not grow up with their biological father being present respectively. Following our definition above, $6.1 \%$ of the individuals were raised

\footnotetext{
${ }^{9}$ Precisely, the father is coded as absent if the child has spent eight years or more with a single mother, a stepfather, other relatives, foster parents, or in a children's home at the age of 15.
} 
without their biological fathers. ${ }^{10}$ Moreover, on average, $16.6 \%$ of the individuals in our sample chose the same occupation as their father (according to the above classification of occupational groups). The fraction is somewhat larger in the subgroup of children whose father was living in the same household during childhood (16.9\%) than in the subgroup of children whose father was absent during their childhood (11.7\%).

The first two columns of Table 4 depict the distribution of individuals across occupational groups. Jobs in sales, administration and the social sector are chosen most often. The third and fourth column show the relative frequencies separately for individuals who were raised in the presence and absence of their biological fathers respectively and demonstrate that occupational choices do not differ significantly across the two groups. Table 5 depicts the intergenerational transmission rates per occupation for the whole sample (first column) and the subsamples of individuals whose father was present and absent during youth (second and third column). Intergenerational persistency differs across occupational groups: children are especially likely to pursue the same occupation as their fathers if the father works as a farmer $(61 \%)$ or as a miner (33\%). Occupations in technical fields $(5 \%)$ and services $(5 \%)$ have, in turn, low transmission rates. The descriptive statistics moreover indicate that intergenerational persistency tends to be somewhat smaller in the group of children whose father was absent during their youth.

- Tables 4 and 5 about here -

The father's influence on the occupational choice of his children furthermore depends on the gender of the offspring. Sons more often pursue a similar occupation as their fathers than daughters. According to our classification of occupational groups, the transmission rate is approximately $20 \%$ for boys and $13 \%$ for girls. Our empirical analysis will account for potential differences in intergenerational persistence of the father's occupation for boys and girls (see Section 4 for details).

\section{Estimation Strategy}

To assess the intergenerational persistency of occupational choices, we follow previous studies and estimate McFadden's choice model (McFadden (1974)) which allows to consider the impact of individual characteristics and occupation-specific variables on the probability that individual $i$ chooses occupation $j$. Formally

\footnotetext{
${ }^{10}$ After World War II, parental mortality and divorce rates were low in Germany. Therefore, the majority of children in our sample were raised by both parents.
} 


$$
\operatorname{Pr}\left(\text { occ }_{i}=j\right)=\frac{\exp \left(\alpha \text { occ }_{-} \text {ath }_{i j}+\beta \text { occ }_{-} \text {fath }_{i j} \times a b s e n t_{i}+\mathbf{x}_{i} \boldsymbol{\beta}_{j}\right)}{\sum_{l=1}^{m} \exp \left(\alpha \text { occ }_{-} f_{a t h}+\beta \text { occ }_{i l} f_{a t h} \times a b s e n t_{i}+\mathbf{x}_{i} \boldsymbol{\beta}_{l}\right)}
$$

where $o c c_{i}$ indicates individual $i$ 's occupational choice. ${ }^{11}$ The variable of main interest is the dummy variable $o c c_{-} f a t h_{i j}$ for the occupation of individual $i$ 's biological father. Intergenerational transmission of occupational choices implies that the probability of choosing an occupation increases if the father works in the same occupation. To disentangle nature-related and nurture-related effects, we include an interaction term between $o c c_{-} f a t h_{i j}$ and a variable indicating whether the biological father was absent during the individual's youth. This allows the effect of the father's occupation to vary across the subsamples of individuals who were raised in families with and without their biological father. As described above, we presume that intergenerational persistence in occupational choices reflects nature and nurture effects in the former subsample, while intergenerational transmission of occupations in the latter subsample is mainly driven by the inheritability of genetic endowments. Differences in the probability of choosing the same occupation as one's father across the two groups thus point to the influence of environmental factors on intergenerational occupational transmissions. Formally, we expect $\alpha>0$ and $\beta<0$. Note that Ai and Norton (2003) suggested that the sign and statistical significance of the coefficient estimate for the interaction term in nonlinear models has no meaningful interpretation. A recent paper by Puhani (2012) qualifies this point though by stressing that in 'difference-in-differences' frameworks (as in our setting) the incremental effect of the coefficient of the interaction term prevails. As a robustness check, we also assess the impact of fathers' occupations on children's occupational choices by running two separate regressions for the subsamples of individuals whose father was present and absent during their youth respectively. ${ }^{12}$

We furthermore include the vector $\mathbf{x}_{i}$ of individual specific control variables. ${ }^{13}$ To avoid results that pick up intergenerational transmission of 'vertical' education choices, we control for the individual's educational level by including information on the years of schooling. Furthermore, control variables for the individual's age, sex and location of residence are included. We also augment the set of regressors by a linear time trend to capture changes in labor market conditions and occupational structures over time. ${ }^{14}$

\footnotetext{
${ }^{11}$ The observational unit is the occupation per individual. The data thus comprises $i \times j$ observations.

${ }^{12}$ Note that test theory states that t-tests cannot be used to test differences between coefficients that result from different estimations though.

${ }^{13}$ Individual specific control variables are included through interaction terms with indicator variables for each alternative, excluding the interaction variable associated with the base alternative.

${ }^{14}$ Note that including dummy variables for the individuals' age groups (not reported) yields similar
} 
One well-known limitation of conditional logit models is that they rely on the rather strong assumption of independence of irrelevant alternatives (IIA). As a robustness check, we thus estimate nested logit models (McFadden (1978)), where IIA must hold in each of the nested groups only. We classify the 19 occupational classes in three nested groups which correspond to broad economic sectors: raw materials, manufacturing, and services. For a mapping between occupational classes and sectors, see Table 1 in the Appendix. ${ }^{15}$

\section{Empirical Results}

The following section presents our estimation results. Tables 6-11 depict the model specifications. Standard errors are reported in brackets.

Table 6 presents the result of the conditional logit model outlined in the previous section. Working in the metal industry is the reference category throughout the section. Column (1) assesses intergenerational occupational transmission in a baseline model without control variables, Column (2) adds additional regressors for the individual's years of education, age, sex, location of residence and a linear time trend. The coefficient estimate for the father's occupation turns out positive and statistically significant in both specifications, thus confirming the notion that children's occupational choices are biased towards their fathers' occupations. Marginal effects for the second model are reported in Column (1) of Table 8 and indicate that intergenerational occupational persistence is quantitatively relevant. Having a father who works in agriculture or forestry for example increases the probability of choosing an agricultural occupation by 3.4 percentage points or around $67 \%$ relative to the unconditional probability for choosing an occupation in agriculture or forestry (5.06\%, see Table 4). For many other occupational groups, the quantitative effects are even larger, implying that the probability for picking an occupation in a particular category doubles if the father pursues an occupation in this group. ${ }^{16}$

As outlined in Equation (1), Specification (3) moreover augments the estimation model by an interaction term between the biological father's occupation and a dummy variable indicating whether the individual's father was absent during his youth. The coefficient estimate for the interaction term turns out negative and statistically sig-

\footnotetext{
results as the ones reported below.

${ }^{15}$ Note that we tested several alternative hierarchical tree structures. The estimation results are comparable to the results presented below. Details are available from the authors upon request.

${ }^{16}$ The quantitatively strong intergenerational occupational transmission confirms earlier findings, e.g. by Ferrie (2005) who report that 60 percent of white collar workers' sons became white collar workers in the U.S. and half of farmers' sons also work as farmers.
} 
nificant suggesting that intergenerational transmission rates in occupational choices are lower for individuals whose biological father was not living in the same household during their youth. Specifications (4) and (5) of Table 6 reestimate the model separately for individuals whose father was present and absent respectively. The results confirm our previous findings. Again, transmission rates in occupational choices tend to be lower for individuals who grew up without their biological fathers. Columns (2) and (3) of Table 8 report the corresponding marginal effects. Quantitatively, marginal effects are, on average, by around $25 \%$ lower if the father was not present during childhood. Following our argumentation in the previous section, the results thus suggest that the intergenerational transmission of occupational choices is not solely driven by the inheritability of talents and preferences but that nurture and environmental factors play a significant role, too.

- Tables 6, 7 and 8 about here -

Furthermore note that the coefficient estimates for the control variables show the expected signs (see Table 7, which reports the estimates for the control variables in Specification (2) of Table 6). Educational attainment has a large and significant effect on occupational choice. High levels of education significantly increase the probability of choosing occupations in technical fields or in the tertiary sector. Low educational attainment in turn significantly increases the likelihood of being a farmer. The linear time trend indicates that older cohorts have a significantly higher probability of working in the agricultural sector or as miners. The results further suggest that women make significantly different occupational choices than men and have an increased probability of working in the tertiary sector, especially in occupations related to administration, sales, education and health.

As outline above, we furthermore assess the robustness of our findings to estimating nested logit models where IIA has to hold for occupations within the same sector only. Working in the manufacturing sector is the reference category for the first level of the decision tree. The results are presented in Table 9. Specification (1) depicts a model for the full sample where the dummy variable indicating the father's occupation is interacted with an indicator for the father's absence during youth. Furthermore, specifications (2) and (3) again reestimate the model separately for individuals whose father was present and absent during their youth respectively. The results confirm our previous findings and suggest that intergenerational occupational transmission is smaller if the biological father was absent during the individual's youth, pointing to 
the importance of nurture effects. The quantitative effects are comparable to the conditional logit results. ${ }^{17}$

- Table 9 about here -

Moreover, as mentioned above, sons and daughters might be influenced differently by their father's occupation. We thus follow previous papers and reestimate our baseline specifications for the subgroup of male individuals. The results of conditional logit estimations are displayed in Table 10. The findings resemble our baseline results and show that occupational choices by male individuals are strongly determined by the occupation of their biological father. The quantitative effect is again smaller for individuals whose father was absent during their childhood though, pointing to nurture effects in the intergenerational transmission of occupational choices. Similar results are found for the subsample of daughters, although, in line with intuition, statistical significance of the transmission effect is weaker than in the subsample of sons. ${ }^{18}$

- Table 10 about here -

Furthermore, the estimation models so far classified fathers as absent if they did not live in the same household for 8 years or more during the individual's childhood. The choice of the cutoff age is somewhat arbitrary and reflects the trade-off between defining a control group of children with an absent father which is sufficiently large (by choosing a high cutoff age), but simultaneously ensuring that nurture effects do not play a role in the individual's occupational choice (by choosing a low cutoff age). As a robustness check we assess the sensitivity of our results to specifying an estimation model that exploits the continuous information of the number of years an individual has spent without his/her biological father before turning 15. Following our argumentation above, we expect that the probability of choosing the father's occupation decreases the longer the biological father did not live in the same household during the child's youth. The results are reported in Table 11 and confirm this notion. The coefficient estimate for the interaction term between the father's occupation and the continuous absence variable is negative and statistically significant in all specifications, indicating that each year spent without the biological father during childhood reduces the intergenerational occupational transmission.

\footnotetext{
${ }^{17} \mathrm{~A}$ likelihood ratio-test shows weak empirical evidence that the IIA assumption does not hold and that nested models increase the validity of the results.

${ }^{18}$ Results for the subgroup of daughters are available from the authors upon request.
} 
Finally, our baseline specifications employ a rather broad definition of an absent father, including family situations where the parents are separated or divorced and the child lives with the mother or other relatives during his/her youth. Although everyday contact with the biological father is unlikely in these settings, we cannot exclude that fathers meet their children on a regular basis, play an active role in their upbringing and may thus also influence their occupational choice. In these cases, the intergenerational transmission of occupational decisions may also be characterized by nurture effects in the subgroup of individuals with an 'absent' father. Differences in intergenerational occupational transmission between individuals with an absent and present father plausibly still reflect nurture effects driven by differences in the intensity of interaction with the biological father, but the quantitative nurture effect is likely to be underestimated and a lower bound to the true effect. As a robustness check we restrict the group of individuals with an absent father to orphans whose father died when they were 7 or younger and thus did not influence the child's occupational choice through advice or role models. The results are presented in Table 12 and resemble the pattern of our baseline findings. Since the subsample of 'absent' individuals shrinks to one third of its initial size, standard errors are somewhat inflated, but the negative coefficient estimate for the interaction term between the indicators for the father's occupation and his absence still turns out marginally significant. Quantitatively, the transmission rates for half-orphans are smaller than the transmission rates for the whole group of individuals whose father was absent during their youth, as expected.

- Table 12 about here -

\section{Summary and Conclusion}

This paper analyzes intergenerational transmission of occupational choices in Germany. Using data from the German SOEP, we find that the probability of choosing a particular occupation is significantly increased if one's father works in the occupation. To determine whether this intergenerational correlation is purely driven by the inheritance of genetic endowments or whether nurture effects also play a significant role, we estimate the model separately for individuals who grew up with their biological father and individuals who did not. While intergenerational occupational transmission in the 
former group plausibly reflects nature and nurture components, the intergenerational correlation in the latter group is largely limited to nature effects. The results suggest positive transmission rates for both subsamples, while the quantitative effect is, on average, around $25 \%$ smaller in the group of individuals whose biological father did not live in the same household during their youth.

The results thus suggest that parents influence the occupational choices of their offspring beyond genetic factors. The nurture-bias towards the parents' occupation may be related to information frictions or strategic parental behaviour and might potentially lead to inferior matches of individual talents and preferences with occupational requirements, implying productivity and wage losses, as well as negative spillovers to the rest of society.

As occupational choices are affected by environmental factors, one policy implication that follows from the analysis is to improve (public) information on the structure, requirements and work routines in potential future occupations which is available to adolescents and provided by other sources than family members. Possible mechanisms might include the implementation of classes on vocational orientation and guidance in schools, mandatory internships for pupils and students, career days and the extension of occupational information and orientation offered by national employment agencies. 


\section{References}

Ai, C. and Norton, E. C. (2003), Interaction Terms in Logit and Probit Models, Economics Letters 80(1), pp. 123-129.

Andersen, R. C., Duru, A., and Reeb., D. M. (2009), Founders, Heirs, and Corporate Opacity in the United States, Journal of Financial Economics 92(2), pp. 205-222.

Anker, R. (1997), Theories of Occupational Segregation by Sex: An Overview, International Labour Review 136(3), pp. 315-339.

Antecol, H. and Cobb-Clark, D. (2010), Do Non-Cognitive Skills Help Explain the Occupational Segregation of Young People?, Melbourne Institute Working Paper Series wp2010n13, Melbourne Institute of Applied Economic and Social Research, The University of Melbourne.

Bennedsen, M. et al. (2007), Inside the Family Firm: The Role of Families in Succession Decisions and Performance, Quarterly Journal of Economics 122(2), pp. 647-691.

Bentolila, S., Michelacci, C., and Suarez, J. (2008), Social Contacts and Occupational Choice, Economica 77(305), pp. 20-45.

Björklund, A., Lindahl, M., and Plug, E. (2006), The Origins of Intergenerational Associations: Lessons from Swedish Adoption Data, Quarterly Journal of Economics 121(3), pp. 999-1028.

Black, S. E. and Devereux, P. J. (2011), Recent Developments in Intergenerational Mobility, in O. C. Ashenfelter and Car (eds.), Handbook of Labor Economics, Amsterdam: North Holland, vol. 4B, chap. 16, pp. 1487-1541.

Boehm, T. and Riedel, N. (2012), On Adverse Selection into Public Civil Service, CESifo Economic Studies Advance Access. First published online: December 29, 2012.

Bouchard, T. J. (2004), Genetic Influence on Human Psychological Traits - A Survey, Current Directions in Psychological Science 13(4), pp. 148-151.

Corak, M. and Piraino, P. (2011), The Intergenerational Transmission of Employers, Journal of Labor Economics 29(1), pp. 37-68.

Corneo, G. and Jeanne, O. (2009), A Theory of Tolerance, Journal of Public Economics 93(5-6), pp. 691-702. 
Das, M. and Sjogren, T. (2002), The Intergenerational Link in Income Mobility: Evidence from Adoptions, Economics Letters 75(1), pp. 55-60.

DeLeire, T. and Levy, H. (2004), Worker Sorting and the Risk of Death on the Job, Journal of Labor Economics 22(4), pp. 210-217.

Doepke, M. and Zilibotti, F. (2008), Occupational Choice and the Spirit of Capitalism, Quarterly Journal of Economics 123(2), pp. 747-793.

Drost, A. (2002), The Dynamics of Occupational Choice: Theory and Evidence, LABOUR: Review of Labour Economics and Industrial Relations 16(2), pp. 201233.

Dunn, T. and Holtz-Eakin, D. (2000), Financial Capital, Human Capital, and the Transition to Self-Employment: Evidence from Intergenerational Links, Journal of Labor Economics 18(2), pp. 282-305.

Ferrie, J. P. (2005), History Lessons The End of American Exceptionalism? Mobility in the United States Since 1850, Journal of Economic Perspectives 19(3), pp. 199-215.

Grazier, S. and Sloane, P.J. (2008), Accident Risk, Gender, Family Status and Occupational Choice in the UK, Labour Economics 15(5), pp. 938-957.

Judge, T. A. and Bono, J. E. (2001), Relationship of Core Self-Evaluations Traits-SelfEsteem, generalized Self-Efficacy, Locus of Control, and emotional Stability-with Job Satisfaction and Job Performance: a Meta-Analysis, Journal of Applied Psychology 86(1), pp. 80-92.

Kleinjans, K. J. (2010), Family Background and Gender Differences in Educational Expectations, Economics Letters 107(2), pp. 125-127.

Krueger, A. B. and Schkade, D. A. (2008), Sorting in the Labor Market: Do Gregarious Workes Flock to Interactive Jobs?, Journal of Human Resources 43(4), pp. 859-883.

Laband, D. N. and Lentz, B. F. (1983), Occupational Inheritance in Agriculture, American Journal of Agricultural Economics 65(2), pp. 311-314.

Laband, D. N. and Lentz, B. F. (1992), Self-Recruitment in the Legal Profession, Journal of Labor Economics 10(2), pp. 182-201.

Lentz, B. F. and Laband, D. N. (1989), Why so many Children of Doctors become Doctors: Nepotism vs. Human Capital Transfers, Journal of Human Resources 24(3), pp. 396-413. 
Lentz, B. F. and Laband, D. N. (1990), Entrepreneurial Success and Occupational Inheritance among Proprietors, Canadian Journal of Economics 23(3), pp. 563-579.

Lins, K. V., Volpin, P., and Wagner, H. F. (2012), Does Family Control Matter? International Evidence from the 2008-2009 Financial Crisis, Review of Financial Studies .

Long, J. and Ferrie, J. (2013), A Tale of Two Labor Markets: Intergenerational Occupational Mobility in Britain and the U.S. Since 1850, American Economic Review forthcoming(11253).

McFadden, D. (1974), Frontiers in Econometrics, in P. Zarembka (ed.), Conditional Logit Analysis of Qualitative Choice Behaviour, New York: Academic Press, pp. $105-142$.

McFadden, D. (1978), Modelling The Choice of Residential Location, in A. Karlkvist, L. Sundqvist, F. Snickars, and J. W. Weibull (eds.), Spatial Interaction Theory and Planning Models, Amsterdam: North Holland, chap. 3, pp. 77-96.

Plug, E. (2004), Estimating the Effect of Mother's Schooling on Children's Schooling Using a Sample of Adoptees, American Economic Review 94(1), pp. 358-368.

Plug, E. and Vijverberg, W. (2005), Does Family Income Matter for Schooling Outcomes? Using Adoptees as a Natural Experiment, Economic Journal 115(506), pp. 879-906.

Polachek, S. W. (1981), Occupational Self-Selection: A Human Capital Approach to Sex Differences in Occupational Structure, Review of Economics and Statistics 63(1), pp. 60-69.

Puhani, P. A. (2012), The Treatment Effect, the Cross Difference, and the Interaction Term in Nonlinear "Difference-in-Differences" Models, Economics Letters 115(1), pp. 85-87.

Robertson, D. and Symons, J. (1990), The Occupational Choice of British Children, Economic Journal 100(402), pp. 828-841.

Sacerdote, B. (2002), The Nature and Nurture of Economic Outcomes, American Economic Review 92(2), pp. 344-348. 
Sacerdote, B. (2007), How Large Are the Effects from Changes in Family Environment? A Study of Korean American Adoptees, Quarterly Journal of Economics 121(1), pp. 119-158.

Scarr, S. and Weinberg, R. A. (1994), Educational and Occupational Achievements of Brothers and Sisters in Adoptive and Biologically Related Families, Behavior Genetics 24(4), pp. 301-325.

Sookram, S. and Strobl, E. (2009), The Role of Educational Choice in Occupational Gender Segregation: Evidence from Trinidad and Tobago Sandra Sookram, Economics of Education Review 28(1), pp. 1-10.

Statistisches Bundesamt (1992), Klassifizierung der Berufe - Systematisches und alphabetisches Verzeichnis der Berufsbenennungen. Ausgabe 1992, Stuttgart: MetzlerPoeschel.

Villalonga, B. and Amit, R. (2006), How do family Ownership, Control, and Management affect Firm Value?, Journal of Financial Economics 80(2), pp. 385-417.

Wagner, G. G., Frick, J. R., and Schupp, J. (2007), The German Socio-Economic Panel Study (SOEP) - Scope, Evolution and Enhancements, Schmollers Jahrbuch 127(1), pp. 139-169. 


\section{Appendix}

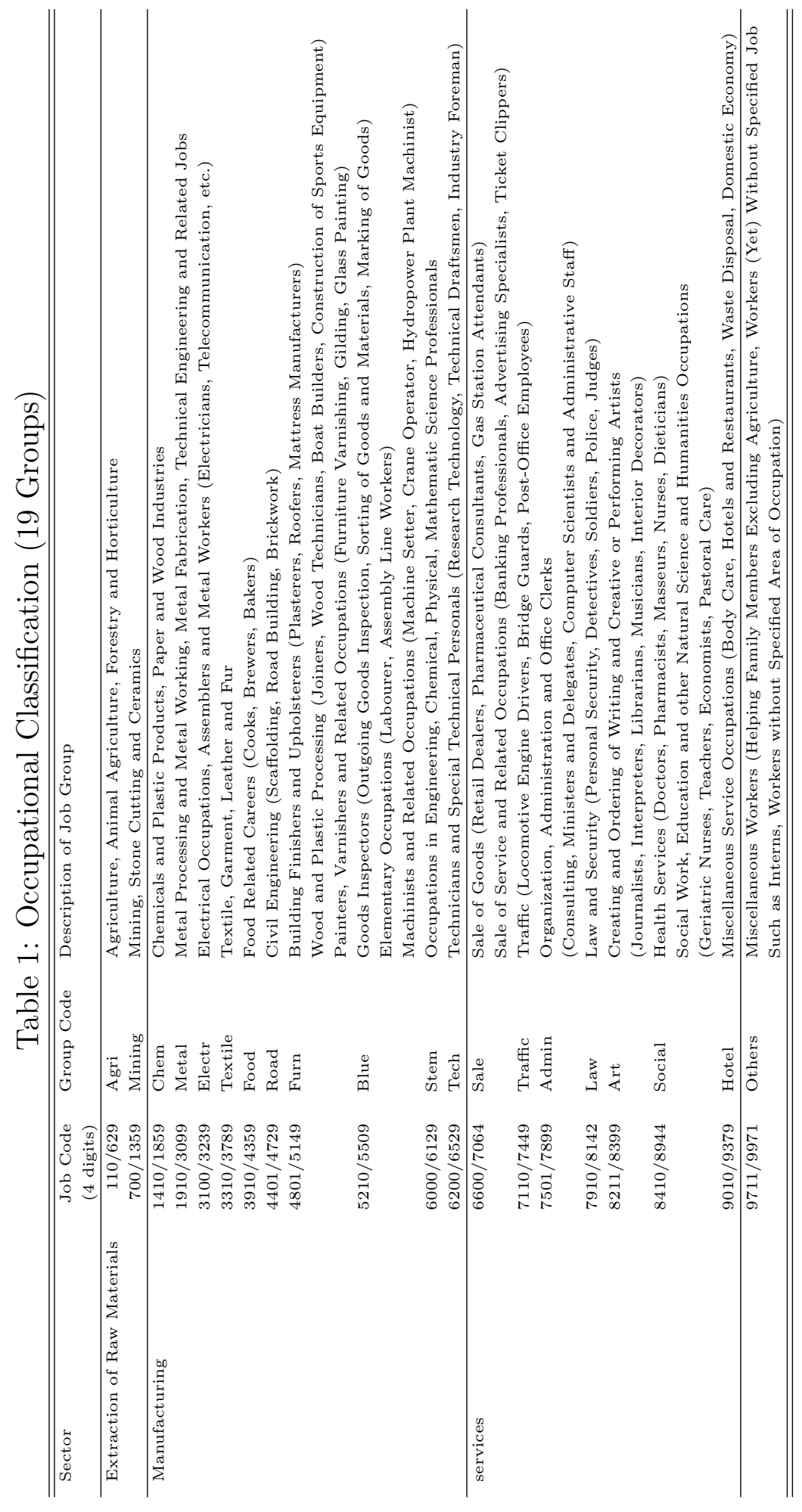


Table 2: Summary Statistics - Full Sample

\begin{tabular}{lccccc}
\hline \hline & $\mathrm{N}$ & Mean & St. Dev. & Min & Max \\
\hline Same Occupation as Father & 6350 & 0.166 & 0.372 & 0 & 1 \\
Biological Father Absent During Youth & 6350 & 0.061 & 0.239 & 0 & 1 \\
Half-Orphan at Age 8 & 6350 & 0.020 & 0.140 & 0 & 1 \\
Female & 6350 & 0.519 & 0.500 & 0 & 1 \\
Years of Education & 6350 & 12.269 & 2.796 & 7 & 18 \\
Year of Birth & 6350 & 1946.57 & 12.541 & 1902 & 1965 \\
Northern Germany & 6350 & 0.226 & 0.418 & 0 & 1 \\
\hline \hline
\end{tabular}

Note: Same occupation as father depicts a dummy variable which takes on the value 1 if the individual's occupation belongs to the same occupational group as his father's occupation, following our classification (see Table 1). The father is defined to be absent during youth if the child has spent at least eight years with a single mother, with a stepfather, with other relatives, with foster parents, or in a children's home at the age of 15 . The dummy variable "half-orphan at age 8" is coded 1 if the child's father died before the child turned 8.

Table 3: Summary Statistics of Individuals with Absent and Present Father

\begin{tabular}{lccccc}
\hline \hline Variable & $\mathrm{N}$ & Mean & Std. Dev. & Min & Max \\
\hline Biological Father Present during Youth & & & \\
Same Occupation as Father & 5965 & 0.169 & 0.375 & 0 & 1 \\
Female & 5965 & 0.520 & 0.500 & 0 & 1 \\
Years of Education & 5965 & 12.285 & 2.797 & 7 & 18 \\
Year of Birth & 5965 & 1946.724 & 12.608 & 1902 & 1965 \\
Northern Germany & 5965 & 0.225 & 0.418 & 0 & 1 \\
\hline Biological Father Absent during Youth & & & \\
Same Occupation as Father & 385 & 0.117 & 0.322 & 0 & 1 \\
Female & 385 & 0.501 & 0.501 & 0 & 1 \\
Years of Education & 385 & 12.014 & 2.760 & 7 & 18 \\
Year of Birth & 385 & 1944.182 & 11.209 & 1913 & 1965 \\
Northern Germany & 385 & 0.244 & 0.430 & 0 & 1 \\
\hline \hline
\end{tabular}

Note: See notes to Table 2 for a definition of the variables. 
Table 4: Distribution of Individuals across Occupational Groups

\begin{tabular}{lrrrr}
\hline \hline & \multicolumn{2}{c}{ Full Sample } & \multicolumn{2}{c}{ Subsamples: Biological Father... } \\
& & & ...Present during & Youth \\
Occupational Group & $\mathrm{N}$ & $\%$ & 5.00 & $\%$ \\
\hline Agri & 321 & 5.06 & 0.62 & 5.97 \\
Mining & 42 & 0.66 & 1.48 & 1.30 \\
Chem & 95 & 1.50 & 10.08 & 1.82 \\
Metal & 658 & 10.36 & 3.65 & 14.81 \\
Electr & 231 & 3.64 & 3.94 & 3.38 \\
Textile & 252 & 3.97 & 2.87 & 4.42 \\
Food & 181 & 2.85 & 1.83 & 2.60 \\
Road & 120 & 1.89 & 3.52 & 2.86 \\
Furn & 223 & 3.51 & 1.49 & 3.38 \\
Blue & 97 & 1.53 & 3.35 & 2.08 \\
Stem & 207 & 3.26 & 2.48 & 1.82 \\
Tech & 155 & 2.44 & 15.39 & 1.82 \\
Sale & 970 & 15.28 & 1.86 & 13.51 \\
Traffic & 119 & 1.87 & 18.26 & 2.08 \\
Admin & 1149 & 18.09 & 1.93 & 15.58 \\
Law & 121 & 1.91 & 1.54 & 1.56 \\
Art & 105 & 1.65 & 14.64 & 3.38 \\
Social & 912 & 14.36 & 6.09 & 10.13 \\
Hotel & 392 & 6.17 & 100.00 & 7.53 \\
Total & 6350 & 100.00 & & 100.00 \\
\hline \hline
\end{tabular}

Note: The first and second column report the absolute number of cases and relative frequencies for each occupational group in the full sample. The third and fourth column show relative frequencies of different occupations for the subsamples of respondents whose biological father was present and absent during youth. See Table 1 for details on the classification of occupations. 
Table 5: Intergenerational Transmission Rates per Occupational Group

\begin{tabular}{lrrr}
\hline \hline Occupational & Full Sample & \multicolumn{2}{c}{ Subsamples: Biological Father... } \\
Group & & Present During Youth & Absent During Youth \\
\hline Agri & 60.75 & 63.09 & 30.43 \\
Mining & 33.33 & 35.14 & 20.00 \\
Chem & 6.32 & 5.68 & 14.29 \\
Metal & 21.88 & 22.46 & 15.79 \\
Electr & 9.52 & 10.09 & 0.00 \\
Textile & 7.54 & 7.66 & 5.88 \\
Food & 17.13 & 17.54 & 10.00 \\
Road & 26.67 & 28.44 & 9.09 \\
Furn & 21.97 & 23.33 & 0.00 \\
Blue & 10.31 & 10.11 & 12.50 \\
Stem & 13.04 & 13.50 & 0.00 \\
Tech & 5.81 & 6.08 & 0.00 \\
Sale & 9.38 & 9.59 & 5.77 \\
Traffic & 16.81 & 17.12 & 12.50 \\
Admin & 20.02 & 20.20 & 16.67 \\
Law & 11.57 & 12.17 & 0.00 \\
Art & 9.52 & 10.87 & 0.00 \\
Social & 12.39 & 12.49 & 10.26 \\
Hotel & 5.10 & 4.13 & 17.24 \\
Total & 16.63 & 16.95 & 11.69 \\
\hline \hline
\end{tabular}

Note: The first column depicts the share of respondents who work in the same occupation as their biological father for the full sample. The second and third column report this information for the subsample of individuals whose father was present and absent during their youth respectively. See Table 1 for details on the classification of occupations. 


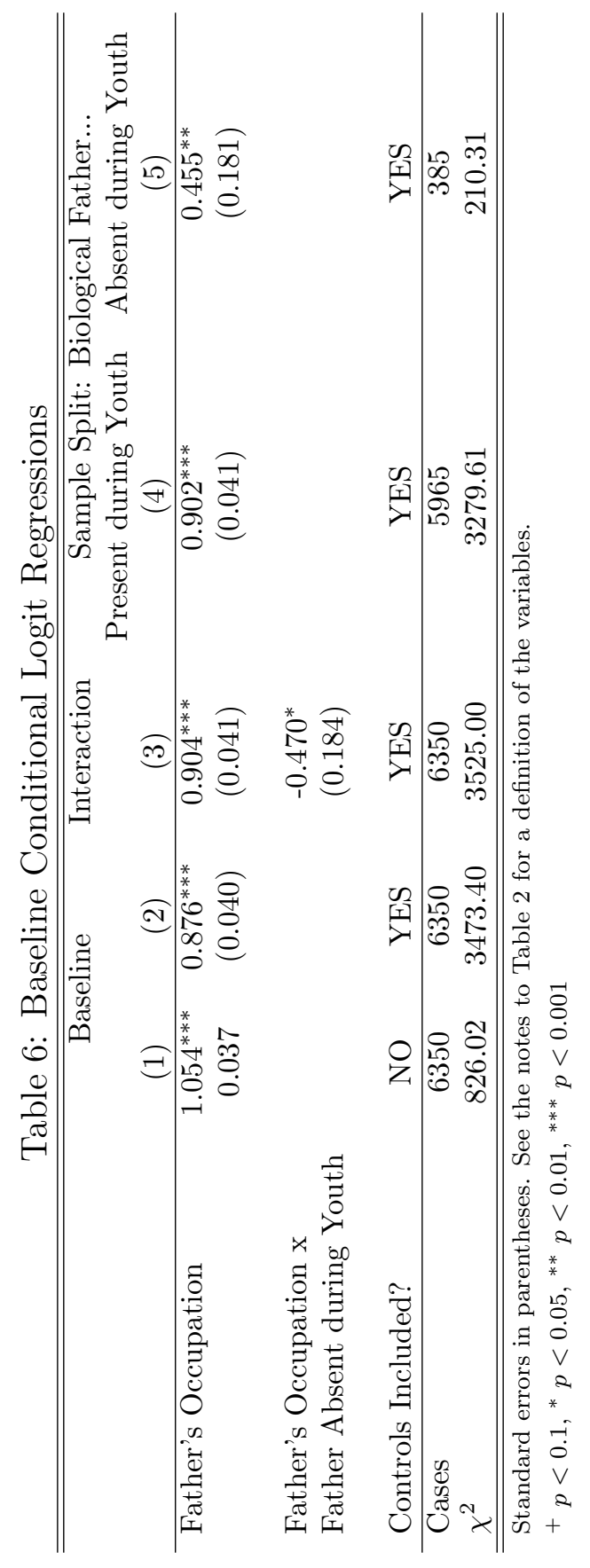




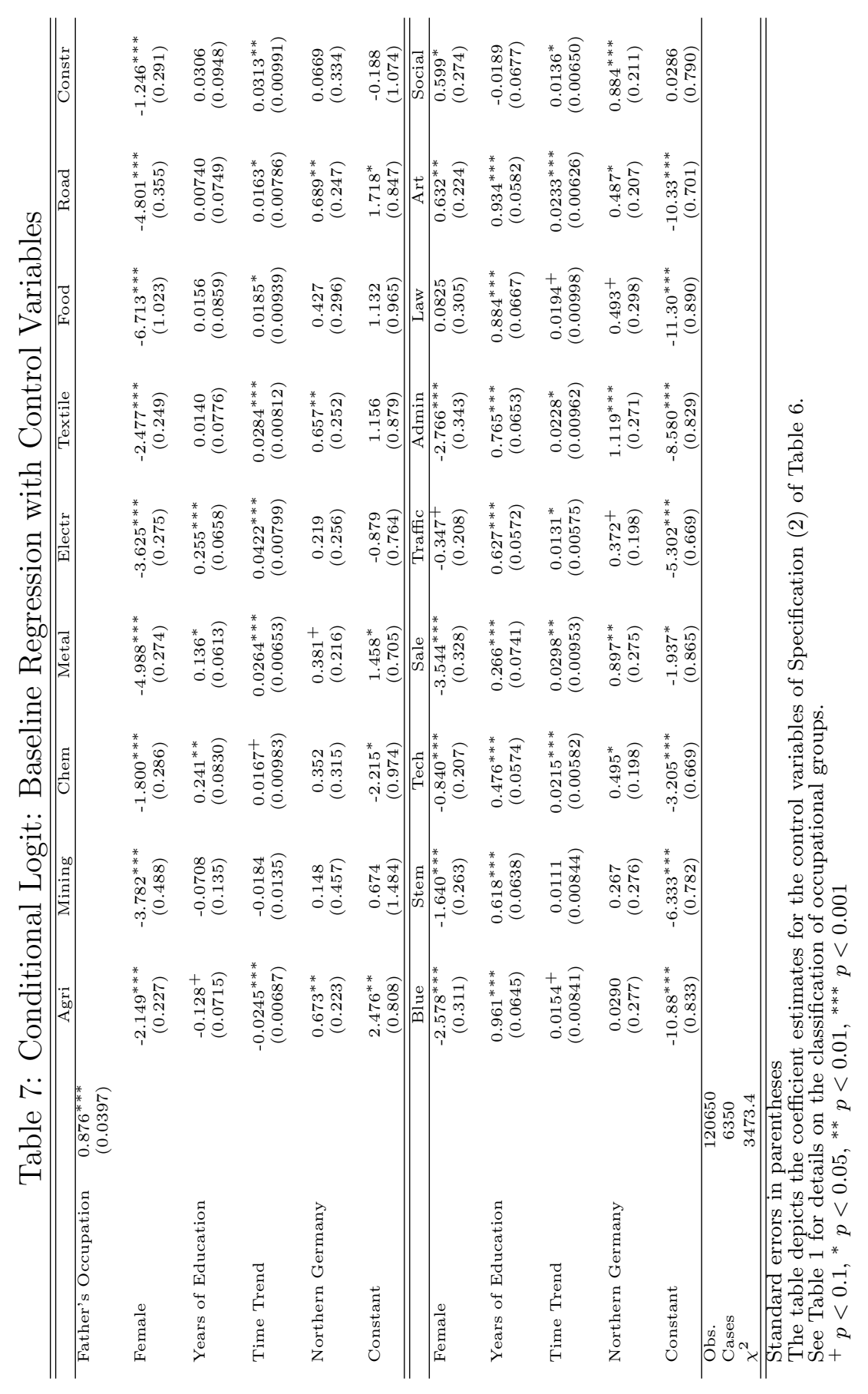


Table 8: Marginal Effects of Conditional Logit Models

\begin{tabular}{|c|c|c|c|}
\hline Occupational Group & $\begin{array}{c}\text { Baseline Model } \\
(1)\end{array}$ & $\begin{array}{c}\text { Biological Father } \\
\text { Present during Youth } \\
(2)\end{array}$ & $\begin{array}{c}\text { Biological Father } \\
\text { Absent during Youth } \\
(3)\end{array}$ \\
\hline Agri & $\begin{array}{c}0.034^{* * *} \\
(0.004)\end{array}$ & $\begin{array}{c}0.035^{* * *} \\
(0.005)\end{array}$ & $\begin{array}{c}0.018 \\
(0.014)\end{array}$ \\
\hline Mining & $\begin{array}{l}0.004^{* *} \\
(0.002)\end{array}$ & $\begin{array}{l}0.005^{* *} \\
(0.002)\end{array}$ & $\begin{array}{c}0.000 \\
(0.001)\end{array}$ \\
\hline Chem & $\begin{array}{c}0.028^{* * *} \\
(0.004)\end{array}$ & $\begin{array}{c}0.029^{* * *} \\
(0.004)\end{array}$ & $\begin{array}{c}0.000 \\
(0.000)\end{array}$ \\
\hline Metal & $\begin{array}{c}0.054^{* * *} \\
(0.006)\end{array}$ & $\begin{array}{c}0.054^{* * *} \\
(0.006)\end{array}$ & $\begin{array}{c}0.047 \\
(0.031)\end{array}$ \\
\hline Electr & $\begin{array}{c}0.043^{* * *} \\
(0.005)\end{array}$ & $\begin{array}{c}0.044^{* * *} \\
(0.005)\end{array}$ & $\begin{array}{c}0.017 \\
(0.014)\end{array}$ \\
\hline Textile & $\begin{array}{c}0.033^{* * *} \\
(0.005)\end{array}$ & $\begin{array}{c}0.035^{* * *} \\
(0.005)\end{array}$ & $\begin{array}{c}0.000 \\
(0.205)\end{array}$ \\
\hline Food & $\begin{array}{c}0.036^{* * *} \\
(0.005)\end{array}$ & $\begin{array}{c}0.038^{* * *} \\
(0.005)\end{array}$ & $\begin{array}{c}0.014 \\
(0.011)\end{array}$ \\
\hline Road & $\begin{array}{l}0.004^{+} \\
(0.002)\end{array}$ & $\begin{array}{l}0.004^{+} \\
(0.002)\end{array}$ & $\begin{array}{c}0.000 \\
(0.008)\end{array}$ \\
\hline Furn & $\begin{array}{c}0.019^{* * *} \\
(0.003)\end{array}$ & $\begin{array}{c}0.019^{* * *} \\
(0.004)\end{array}$ & $\begin{array}{c}0.012 \\
(0.011)\end{array}$ \\
\hline Blue & $\begin{array}{c}0.020^{* * *} \\
(0.003)\end{array}$ & $\begin{array}{c}0.016^{* * *} \\
(0.003)\end{array}$ & $\begin{array}{c}0.017 \\
(0.014)\end{array}$ \\
\hline Stem & $\begin{array}{c}0.021^{* * *} \\
(0.003)\end{array}$ & $\begin{array}{c}0.022^{\text {*** }} \\
(0.004)\end{array}$ & $\begin{array}{c}0.000 \\
(0.141)\end{array}$ \\
\hline Tech & $\begin{array}{c}0.049^{* * *} \\
(0.005)\end{array}$ & $\begin{array}{c}0.051^{* * *} \\
(0.005)\end{array}$ & $\begin{array}{c}0.020 \\
(0.015)\end{array}$ \\
\hline Sale & $\begin{array}{c}0.191^{* * *} \\
(0.010)\end{array}$ & $\begin{array}{c}0.198^{* * *} \\
(0.010)\end{array}$ & $\begin{array}{l}0.092^{*} \\
(0.047)\end{array}$ \\
\hline Traffic & $\begin{array}{c}0.022^{* * *} \\
(0.003)\end{array}$ & $\begin{array}{c}0.021^{* * *} \\
(0.004)\end{array}$ & $\begin{array}{c}0.018 \\
(0.014)\end{array}$ \\
\hline Admin & $\begin{array}{c}0.194^{* * *} \\
(0.010)\end{array}$ & $\begin{array}{c}0.200^{* * *} \\
(0.010)\end{array}$ & $\begin{array}{l}0.098^{*} \\
(0.047)\end{array}$ \\
\hline Law & $\begin{array}{c}0.022^{* * *} \\
(0.003)\end{array}$ & $\begin{array}{c}0.024^{* * *} \\
(0.004)\end{array}$ & $\begin{array}{c}0.000 \\
(0.003)\end{array}$ \\
\hline Art & $\begin{array}{c}0.023^{* * *} \\
(0.003)\end{array}$ & $\begin{array}{c}0.024^{* * *} \\
(0.004)\end{array}$ & $\begin{array}{c}0.012 \\
(0.010)\end{array}$ \\
\hline Social & $\begin{array}{c}0.121^{* * *} \\
(0.008)\end{array}$ & $\begin{array}{c}0.128^{* * *} \\
(0.009)\end{array}$ & $\begin{array}{c}0.043 \\
(0.028)\end{array}$ \\
\hline Hotel & $\begin{array}{c}0.042^{* * *} \\
(0.005)\end{array}$ & $\begin{array}{c}0.046^{* * *} \\
(0.006)\end{array}$ & $\begin{array}{c}0.009 \\
(0.008)\end{array}$ \\
\hline
\end{tabular}

The table presents marginal effects for the models presented in Columns (2), (4) and (5) of Table 6. Standard errors in parentheses.

$+p<0.1,{ }^{*} p<0.05,{ }^{* *} p<0.01,{ }^{* * *} p<0.001$ 
Table 9: Nested Logit Model

\begin{tabular}{|c|c|c|c|}
\hline & \multirow[t]{2}{*}{ Interaction } & \multicolumn{2}{|c|}{ Sample Split: Biological Father... } \\
\hline & & Present during Youth & Absent during Youth \\
\hline \multirow[t]{2}{*}{ Father's Occupation } & $1.188^{* * *}$ & $1.224^{* * *}$ & $0.815^{+}$ \\
\hline & $(0.088)$ & $(0.087)$ & $(0.436)$ \\
\hline Father's Occupation x & $-0.655^{* *}$ & & \\
\hline Father Absent during Youth & $(0.215)$ & & \\
\hline Controls Included? & YES & YES & YES \\
\hline Cases & 6350 & 5965 & 385 \\
\hline$\chi^{2}$ & 1227.04 & 1130.50 & 38.77 \\
\hline
\end{tabular}

Standard errors in parentheses. See the notes to Table 2 for a definition of the variables.

$+p<0.1,{ }^{*} p<0.05,{ }^{* *} p<0.01,{ }^{* * *} p<0.001$

Table 10: Sample Restriction to Male Individuals

\begin{tabular}{lcc}
\hline \hline Father's Occupation & $\begin{array}{c}1.298^{* * *} \\
(0.050)\end{array}$ & $\begin{array}{c}1.051^{* * *} \\
(0.052)\end{array}$ \\
& $-0.891^{* * *}$ & $-0.901^{* *}$ \\
Father's Occupation x & $(0.255)$ & $(0.273)$ \\
Father Absent during Youth & $\mathrm{NO}$ & YES \\
Controls Included? & 3053 & 3053 \\
Cases & 689.14 & 1384.71 \\
$\chi^{2}$ & & \\
\hline \hline & The table presents the estimation results of a conditional logit model. \\
Standard errors in parentheses. See the notes to Table 2 for a definition of the variables. \\
$+p<0.1,{ }^{*} p<0.05,{ }^{* *} p<0.01,{ }^{* * *} p<0.001$
\end{tabular}


Table 11: Continuous Definition of Absent Father

\begin{tabular}{|c|c|c|}
\hline Father's Occupation & $\begin{array}{c}1.080^{* * *} \\
(0.038)\end{array}$ & $\begin{array}{c}0.904^{* * *} \\
(0.041)\end{array}$ \\
\hline $\begin{array}{l}\text { Father's Occupation x } \\
\text { Years without Father before } 15\end{array}$ & $\begin{array}{l}-0.033^{*} \\
(0.014)\end{array}$ & $\begin{array}{l}-0.034^{*} \\
(0.015)\end{array}$ \\
\hline Controls Included? & NO & YES \\
\hline Cases & 6344 & 6344 \\
\hline$\chi^{2}$ & 834.65 & 3520.51 \\
\hline
\end{tabular}

Table 12: Control Group Restricted to Half-Orphans at Age 8

\begin{tabular}{lcc}
\hline \hline Father's Occupation & $\begin{array}{c}1.080^{* * *} \\
(0.038)\end{array}$ & $\begin{array}{c}0.902^{* * *} \\
(0.041)\end{array}$ \\
& & $-0.614^{+}$ \\
Father's Occupation $\mathrm{x}$ & -0.476 & $(0.337)$ \\
Half-Orphan & $(0.306)$ & $\mathrm{YES}$ \\
Controls Included? & $\mathrm{NO}$ & 6092 \\
\hline Cases & 6092 & 3399.45 \\
$\chi^{2}$ & 825.58 & \\
\hline The table presents the estimation results of a conditional logit model. \\
Standard errors in parentheses. See the notes to Table 2 for a definition of the variables. \\
$+p<0.1,{ }^{*} p<0.05,{ }^{* *} p<0.01,{ }^{* * *} p<0.001$
\end{tabular}

